\title{
INACTIVATION OF THE ODONTOGENIC AMELOBLAST-ASSOCIATED GENE AFFECTS THE INTEGRITY OF THE JUNCTIONAL EPITHELIUM AND GINGIVAL HEALING
}

\author{
R.M. Wazen ${ }^{1 \S}$, P. Moffatt ${ }^{2,3 \S}$, K.J. Ponce ${ }^{1}$, S. Kuroda ${ }^{1}$, C. Nishio ${ }^{4}$ and A. Nanci ${ }^{1,5 *}$ \\ ${ }^{1}$ Laboratory for the Study of Calcified Tissues and Biomaterials, Department of Stomatology, Faculty of Dentistry, \\ Université de Montréal, Montréal, Québec, Canada. \\ ${ }^{2}$ Shriners Hospital for Children, Montréal, Québec, Canada. \\ ${ }^{3}$ Department of Human Genetics, McGill University, Montréal, Québec, Canada. \\ ${ }^{4}$ Department of Oral Health, Section of Orthodontics, Faculty of Dentistry, Université de Montréal, Montréal, \\ Québec, Canada. \\ ${ }^{5}$ Department of Biochemistry and Molecular Medicine, Université de Montréal, Montréal, Québec, Canada.
}

§ These two authors contributed equally to the work

\begin{abstract}
Odontogenic ameloblast-associated (ODAM) belongs to the secretory calcium-binding phosphoprotein (SCPP) gene cluster. It is expressed by the epithelial ameloblasts during the accrued mineralisation of enamel and by cells of the junctional epithelium (JE), a specialised portion of the gingiva that plays a critical role in periodontal health. In both cases, ODAM localises at the interface between the cells and the tooth surface. It is also present among the cells of the JE, and is distinctively highly expressed in many epithelial tumours. ODAM has been proposed to be a matricellular protein implicated in the adhesion of epithelial cells to tooth surfaces, and possibly in mediating cell status. To gain further understanding of the role of ODAM, we have created an Odam knockout (KO) mouse by deleting coding exons 2-6. Inactivation of the gene was verified by Southern blot, PCR, real-time qPCR and loss of immunostaining for the protein. Young Odam KO mice showed no readily apparent phenotype. No significant differences were observed in enamel volume and density, rod-interrod organisation, and its attrition. However, in older animals, the JE presented some detachment, an increase in inflammatory infiltrate, and apical down-growth. In addition, its regeneration was delayed following a gingivectomy challenge. Our results indicate that inactivation of Odam expression has no dramatic consequence on enamel but the phenotype in older animals replicates some JE changes seen during human periodontal disease. Altogether, our results suggest that ODAM plays a role in maintaining integrity of the JE.
\end{abstract}

Keywords: Odontogenic ameloblast-associated, enamel organ, junctional epithelium.

*Address for correspondence:

Antonio Nanci

PO Box 6128, Station Centre-Ville

Montreal, QC, Canada, H3C 3J4

Telephone number: +1 514 343-5846

Fax number: +1 514 343-2233

Email: antonio.nanci@umontreal.ca

\section{Introduction}

The formation of mineralised tissues is a tightly regulated process that implicates, among others, various members of the secretory calcium-binding phosphoprotein (SCPP) cluster (Kawasaki, 2009). This family of genes evolved by tandem duplication from the secreted protein acidic and rich in cysteine-like 1 (Sparcl1) gene. They encode for proteins that stabilise $\mathrm{Ca}$ and $\mathrm{PO}_{4}$ ions in body fluids and/or guide $\mathrm{CaPO}_{4}$ deposition into receptive extracellular matrices (Kawasaki, 2011). Enamel organ screens first reported some new enamel-related genes that belong to this cluster (Bonass et al., 1998; Moffatt et al., 2006a). Among these were amelotin (Amtn) (Iwasaki et al., 2005; Moffatt et al., 2006b), odontogenic ameloblast-associated (Odam, originally termed as APin) (Moffatt et al., 2008), and SCPP-Proline/Glutamine (P/Q)-rich-1 (Scpppq1) (Kawasaki, 2009; Moffatt et al., 2014). The three proteins are expressed in maturation stage ameloblasts, and also by the gingival cells that form the junctional epithelium (JE) (Moffatt et al., 2008; Moffatt et al., 2006b; Moffatt et al., 2014). After enamel maturation, ameloblasts and associated cells give rise to the reduced enamel organ, which fuses with the oral epithelium as the tooth erupts into the oral cavity to form the primary JE. The later is replaced in time by a JE derived solely from the gingival epithelium (Nanci and Bosshardt, 2006). The JE is distinctive because it is an incompletely-differentiated epithelium and its cells do not keratinise (Bosshardt and Lang, 2005). It plays a critical role in oral health by forming a 'collar' around the tooth crown, essentially sealing off periodontal tissues from the aggressive oral environment. Periodontal diseases set in when the structure of the JE starts to fail.

Our interest has focused on ODAM because it is found both at the cell-tooth interface where there is an atypical basal lamina (BL) and because of its persistent presence throughout the JE (Dos Santos et al., 2012; Moffatt et al., 2008; Nishio et al., 2010). Surprisingly, ODAM is also highly upregulated in a number of epithelial cancers whose tissues of origin do not produce the protein, and it has been suggested that it may have a functional role in the pathogenesis of epithelial malignancies (Aung et al., 2006; Kestler et al., 2011; Kestler et al., 2008; Murphy et al., 2008; Siddiqui et al., 2009). Its association with cells and extracellular matrix (the BL) and its temporo-spatial 
distribution during JE formation and regeneration has led us to postulate that similarly to other SCPP members it behaves like a multifunctional matricellular protein (Nishio et al., 2013). ODAM may thereby be part of the molecular mechanisms that allow the JE to adhere to tooth surface, maintain its integrity and acquire its incompletely differentiated cellular status.

Our objective was to gain further insight into the function of ODAM by creating an Odam knockout (KO) mouse model and characterising its phenotype. Initial analyses of the $\mathrm{KO}$ revealed a mild phenotype. Since some KO mouse models only exhibit discernable alterations when animals are subjected to environmental or biomechanical challenges (Malaval et al., 2008; Rittling and Novick, 1997; Wade-Gueye et al., 2010; Yoshitake et al., 1999), we have therefore challenged our Odam KO mice by (1) placing them for extended periods of time in a conventional non-sterile vivarium (replicating conditions leading to periodontal disease) and (2) injuring the JE by gingivectomy to induce its regeneration. Altogether, the results we have found replicate some of the structural changes seen during human periodontal disease and suggest that ODAM plays a role in maintaining periodontal integrity.

\section{Materials and Methods}

All experimental protocols and animal handling were approved by the Comité de déontologie de l'expérimentation sur les animaux of Université de Montréal.

\section{Generation and genotyping of mice lacking full- length Odam}

The targeting vector and recombination strategy for the creation of Odam KO mice are illustrated in Fig. 1a-c. The targeting vector contains the PGK-Neo cassette flanked by 2 homology arms. The $5^{\prime}$ arm is a $3.57 \mathrm{~kb}$ genomic segment ending at the natural ATG codon, while the 3 ' arm is a $2.11 \mathrm{~kb}$ fragment that starts in intron 6 and extends through beginning of intron 8 . The beta-galactosidase gene tagged at its $\mathrm{N}$-terminus with a nuclear localisation signal (NLS-LacZ) was inserted immediately downstream and in frame with the natural ATG codon of the Odam gene. The targeted locus has the Odam coding exons 2 to 6 replaced by the NLS-LacZ and PGK-Neomycin cassettes and created a null allele. The Odam targeting vector was electroporated into R1 ES cells and G418 resistant colonies analysed for the presence of the disrupted Odam gene by Southern blot using 5' or 3' probes lying outside the targeting fragment. Mouse chimeras were generated by injection of mutant ES cell clones into B6C3F1 blastocysts (Hogan et al., 1994) at the McGill Transgenic Core Facility (McGill University, Montreal, QC, Canada). Mutant mice were analysed in a genetic $\mathrm{C} 57 \mathrm{BL} / 6$ background. The colony was maintained using the 1 male/ 2 females mating approach for heterozygote-heterozygote (HET x HET) crosses. Genotyping was done by Southern blotting (Fig. 1d) and PCR analysis (Fig. 1e) of genomic DNA extracted from mouse tail clips, using primers for the targeted allele (5'GAGCCTAACAATCACCTGCC3' (forward) and
5'GCCCGTCTTCTACCTTTCTC3' (reverse) and for the wild type(WT) allele (5'GAGCCTAACAATCACCTGCC3' (forward) and 5'AGCACAATGAAACACTTACCG3' (reverse)).

\section{Housing}

Mice were normally housed in a sterile, specific pathogenfree animal facility in which ventilated-cages, water, food and bedding were autoclaved. Some mice were placed for $1,3,6,12$ months in a conventional non-sterile facility.

\section{Beta-galactosidase staining}

Postnatal day 21 Odam WT, HET and KO mice were anaesthetised with $20 \%$ chloral hydrate solution $(0.4 \mathrm{mg} / \mathrm{g}$ body weight; Sigma-Aldrich Canada Ltd, Oakville, ON, Canada), sacrificed and processed for beta-galactosidase staining (Loughna and Henderson, 2007). Maxillae and mandibles were harvested, washed in $0.1 \mathrm{M}$ phosphatebuffered solution (PB) ( $\mathrm{pH}$ 7.2) and then immersed for $3 \mathrm{~h}$ in LacZ fixative consisting in $1 \%$ paraformaldehyde (Fisher Scientific), $0.2 \%$ glutaraldehyde (Electron Microscopy Sciences, Washington, PA, USA), $2 \mathrm{mM}$ $\mathrm{MgCl}_{2}$ (Fisher Scientific), $5 \mathrm{mM}$ Ethylene glycol-bis (2-aminoethylether)- $N, N, N^{\prime}, N^{\prime}$-tetraacetic acid (SigmaAldrich Canada Ltd), 0.2 \% Nonidet-P40 (NP40, SigmaAldrich Canada Ltd). Tissues were then washed in $0.1 \mathrm{M}$ PB with $2 \mathrm{mM} \mathrm{MgCl}_{2}, 0.01 \%$ sodium deoxycholate (Sigma-Aldrich Canada Ltd) and $0.02 \%$ NP40. Tissues were then incubated at $37^{\circ} \mathrm{C}$ for $4 \mathrm{~h}$ in freshly prepared $\mathrm{X}$-gal staining buffer containing $0.1 \% \mathrm{X}$-gal (Life Technologies ${ }^{\mathrm{TM}}$, Mississauga, ON, Canada), $5 \mathrm{mM}$ potassium ferricyanide (Sigma-Aldrich Canada Ltd), $5 \mathrm{mM}$ potassium ferrocyanide (Sigma-Aldrich Canada Ltd), $2 \mathrm{mM} \mathrm{MgCl}_{2}, 0.01 \%$ sodium deoxycholate and $0.02 \%$ NP40. Tissue were rinsed with $0.1 \mathrm{M} \mathrm{PB}$, post-fixed overnight with $4 \%$ paraformaldehyde and then decalcified in $10 \%$ ethylenediamine tetraacetic acid (EDTA, Fisher Scientific, Whitby, ON, Canada) up to $14 \mathrm{~d}$ according to the age of the mice. Decalcified tissues were washed in $0.1 \mathrm{M}$ $\mathrm{PB}$, embedded in paraffin, sectioned with a Leica RM2155 microtome (Leica Microsystems Canada Inc, Richmond Hill, ON, Canada) and counterstained with haematoxylin and eosin. Sections were observed under the AxioImager M2 light microscope (Carl Zeiss, Oberkochen, Germany).

\section{Sample preparation for RNA extraction and quantitative real-time PCR}

Odam WT, HET, KO mice $(n=2)$ were anaesthetised with $20 \%$ chloral hydrate solution $(0.4 \mathrm{mg} / \mathrm{g}$ body weight $)$ and ketamine hydrochloride $\left(10 \mathrm{mg} / \mathrm{kg}\right.$, Ketaset ${ }^{\circledR}$, Wyeth Canada, St-Laurent, QC, Canada) and sacrificed; hemimandibles were dissected and directly immersed in liquid nitrogen for at least $5 \mathrm{~h}$, and then freeze-dried at $-80{ }^{\circ} \mathrm{C}$ for two days on a $12-\mathrm{L}$ cascade lyophiliser system (Labconco; Kansas City, MO, USA). Whole mandibles were placed in the Trizol ${ }^{\circledR}$ reagent (Life Technologies ${ }^{\mathrm{TM}}$ ) and homogenised for total RNA extraction. For real-time qPCR, cDNA were prepared using the High Capacity cDNA synthesis kit (Applied Biosystems, Life Technologies ${ }^{\mathrm{TM}}$ ). Real-time qPCR was performed on an Applied Biosystems 7500 PCR machine in $25 \mu \mathrm{L}$ reaction volume with the $2 \times$ 
a WT allele

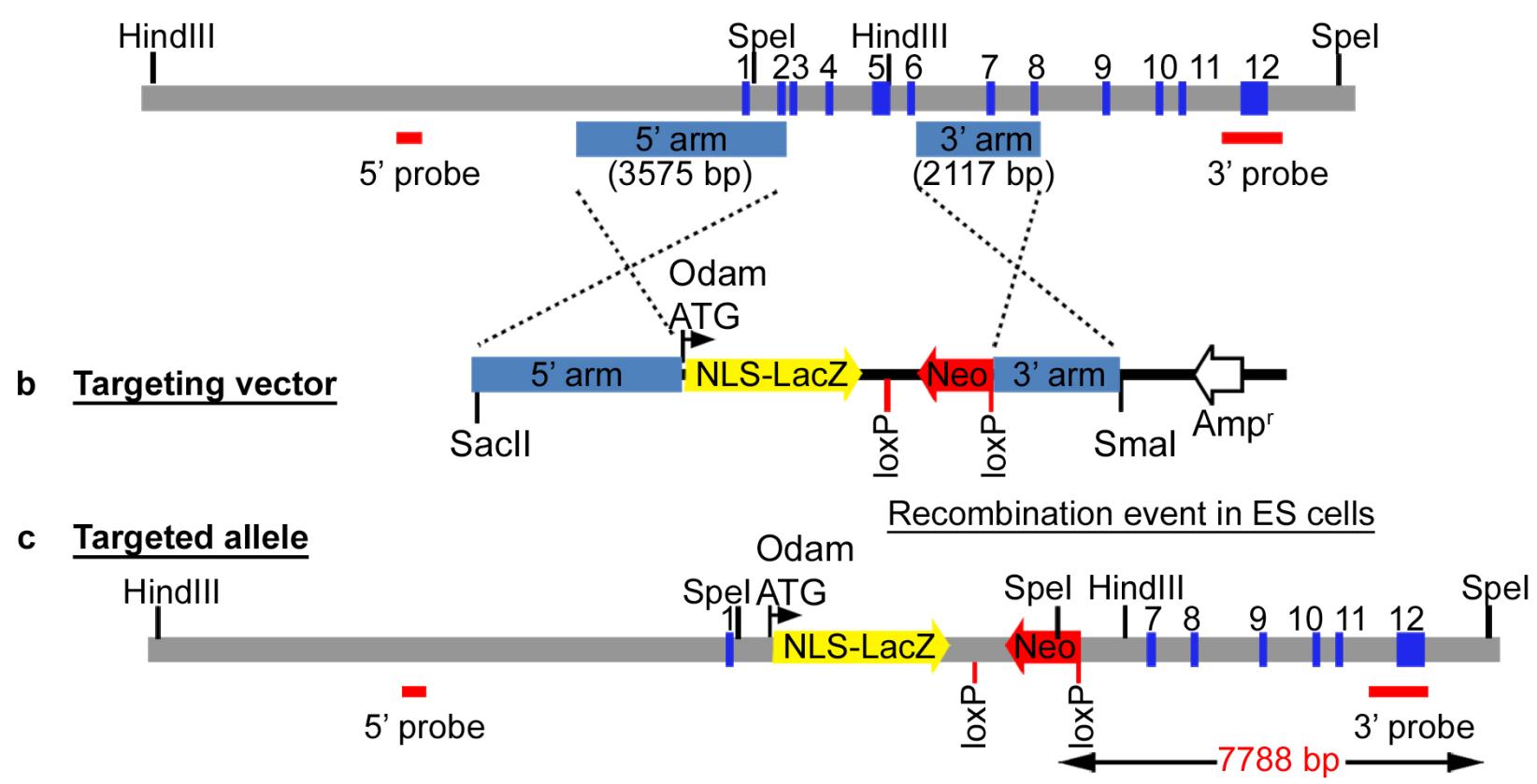

d

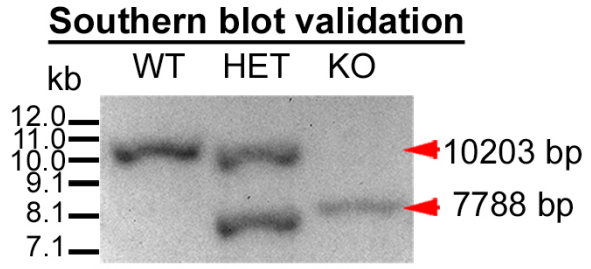

e

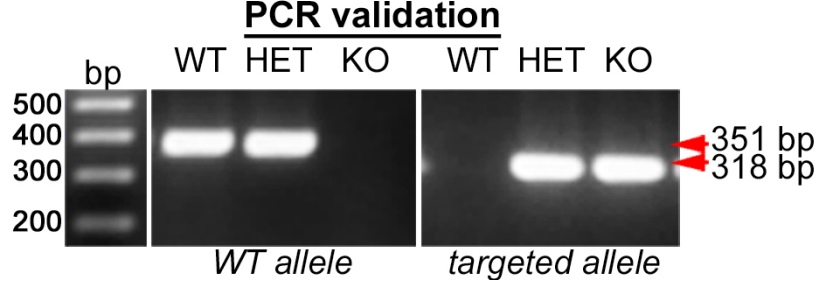

Fig. 1: Generation of Odam KO mice. The Odam locus on chromosome 5 (a) is depicted with exons and location of the region used for homologous recombination in ES cells. The targeting strategy involves deletion of the region starting at the initiator ATG within exon 2, through to exon 6. The portion deleted corresponds to ODAM protein residues 2-139 including the signal peptide. The targeting vector (b) comprises the 5' and 3' homology arms, flanking a cassette encoding the nuclear-beta-galactosidase gene (NLS-LacZ) cloned in frame with the native Odam ATG. The targeted allele (c) will exhibit NLS-LacZ expression under regulation from the normal Odam gene promoter. (d) Genomic DNA isolated from tails was digested with SpeI and analysed by Southern blotting using the 3' probe. The WT and KO allele were detected as 10203 bp and 7788 bp fragments, respectively. (e) PCR analyses with two primers also confirmed the genotype.

Universal PCR Master Mix and the following Taqman probes (Applied Biosystems): Odam (Mm02581570_m1 [exons 6-7] and Mm02581573_m1 [exons 9-10]), Amtn (Mm01351628_m1), Alkaline phosphatase (Tnalp) (Mm00475834_m1), Scpppq1 (Mm03990687_m1) and Cytokeratin 14 (CK 14) (Mm00516876_m1). All data are normalised to $\beta$-actin and values were expressed as $2^{(-\Delta C t)}$.

Tissue processing for light and electron microscopy Odam WT, HET, KO mice (1, 3, 6, 12 months old) housed in sterile and non-sterile animal facility were anaesthetised with $20 \%$ chloral hydrate solution and ketamine hydrochloride and sacrificed by perfusion through the left ventricle with Ringer's lactate (Hospira, Montreal, QC, Canada) for $30 \mathrm{~s}$, followed by a fixative solution consisting of $4 \%$ paraformaldehyde and $0.1 \%$ glutaraldehyde in $0.1 \mathrm{M} \mathrm{PB}$ saline (PBS) buffer ( $\mathrm{pH}$ 7.2) for $20 \mathrm{~min}$. Hemimandibles and hemimaxillae were dissected, and specimens were immersed in the same fixative solution overnight at $4^{\circ} \mathrm{C}$. Specimens were decalcified with $4.13 \%$
EDTA for $21 \mathrm{~d}$ and then were washed for $24 \mathrm{~h}$ in $0.1 \mathrm{M}$ PBS buffer, $\mathrm{pH}$ 7.2.

Some decalcified specimens were processed for paraffin embedding. 5- $\mu \mathrm{m}$ thick sections were prepared with a Leica RM2155 microtome and mounted on Superfrost ${ }^{\circledR} /$ Plus slides (Fisher Scientific) for immunoperoxidase staining.

Some decalcified specimens were post-fixed in potassium ferrocyanide-reduced osmium tetroxide (Neiss, 1984) and then processed for embedding in Epoxy (Electron Microscopy Sciences, Washington, PA, USA) or LR White resin (London Resin Company; Berkshire, UK). 1- $\mu \mathrm{m}$ thick sections were cut with glass knives on a Reichert Jung Ultracut E ultramicrotome and stained with toluidine blue. Ultrathin $80-100 \mathrm{~nm}$ sections were cut with a diamond knife, transferred onto Formvar ${ }^{\circledR}$-coated (polyvinyl formate) 200-mesh nickel grids, stained with $4 \%$ aqueous uranyl acetate for $8 \mathrm{~min}$ and with lead citrate for $2 \mathrm{~min}$, and examined at $80 \mathrm{kV}$ with a FEI Tecnai 12 (FEI, Eindhoven, The Netherlands) transmission electron microscope. 


\section{Regeneration of the JE}

One-year old Odam WT, HET and KO mice were anaesthetised with an intraperitoneal injection of a mixture of $50 \mathrm{mg} / \mathrm{kg}$ of ketamine hydrochloride, $5 \mathrm{mg} / \mathrm{kg}$ of xylazine (Rompun $^{\circledR}$, Bayer Inc., Toronto, ON, Canada), $1 \mathrm{mg} / \mathrm{kg}$ of acepromazine maleate (Acevet 10, Vétoquinol, Lavaltrie, QC, Canada) in distilled water. Removal of the gingiva and the JE along the maxillary molars (gingivectomy) was accomplished by scraping the tooth surface and extending $2 \mathrm{~mm}$ along the palate with periodontal curettes (SU 15/33, SL 5/6 and KS 1/2; Hu-Friedy, Chicago, IL, USA) (Nishio et al., 2010). Gingivectomies were carried out on the left side of maxilla and the contralateral side was left intact as control. Following surgery, animals received a single injection of buprenorphine hydrochloride (Temgesic ${ }^{\mathbb{B}}$, Reckitt and Colman, Hull, UK). Mice were sacrificed at 3, 7 and $14 \mathrm{~d}$ post-surgery and specimens were decalcified and processed for paraffin embedding.

\section{Scanning electron microscope observations (SEM) and micro-tomography (Micro-CT) analysis}

In calcified hemimandibles from 6-months old animals $(n=6)$, the incisal tip was sectioned and etched using nitric acid $0.5 \%(30 \mathrm{~s})$. Samples were examined by backscattered electron imaging (BEI) on a JEOL JSM6460LV variable pressure SEM (25 kV, 50-70 Pa, JEOL, Tokyo, Japan). Some calcified hemimandibles fixed for histological analysis were embedded in Epoxy resin and sagittal sections were prepared using an Isomet ${ }^{\circledR}$ low-speed saw and a diamond disk (Buehler Canada, Markham, ON, Canada). Grey scale values achieved by backscatter signals provide information on mineral distribution and density within tissues (Boskey, 2006).

Fixed calcified hemimandibles from 6-months old animals $(n=6)$ were scanned with a desktop MicroCT scanning system (SkyScan 1072, Bruker SkyScan, Aartselaar, Belgium) in the Center for Bone and Periodontal Research (McGill University, Montreal, QC, Canada). The scanner was operated at $80 \mathrm{kV} / 124 \mu \mathrm{A}$ with a resolution of $12.78 \mu \mathrm{m} /$ pixel and an aluminium filter of $0.25 \mathrm{~mm}$. The sample rotated at $0.9^{\circ} / \mathrm{step}$ for $180^{\circ}$ with an exposure time of $4.4 \mathrm{~s} / \mathrm{step}$ during the scan period. The set of x-ray shadow images obtained from scanning was then reconstructed using the NRecon software (version 1.6.1.3, Bruker SkyScan). The CT-Analyser software (version 1.10.0.1, Bruker SkyScan) was used for the creation of 3D models and 3D quantitative analyses. Total of 12 volume of interests (VOI), with a thickness of $0.25 \mathrm{~mm}$ for each VOI, were built along the incisor, starting from the appearance of the root of the $3^{\text {rd }}$ molar. In each VOI, the enamel boundary was manually outlined with exclusion of non-enamel objects. Enamel volumes were determined from the manually drawn VOI. The threshold for enamel analysis of all VOIs along incisor was set individually for each sample based on the VOI in the erupted portion of the incisor where the enamel is completely matured. Total enamel volume was also calculated using this software and the lower and upper thresholds were defined to be from 165 to 255 grayscale units on an 8-bit grayscale.

\section{Immunohistochemistry}

Immunohistochemistry was performed on $5 \mu \mathrm{m}$ thick sections mounted on Superfrost ${ }^{\circledR} /$ Plus slides. Briefly, deparaffinised sections were first blocked for $20 \mathrm{~min}$, with a solution consisting of $0.01 \mathrm{M} \mathrm{PBS}, \mathrm{pH} 7.2$, containing $0.05 \%$ Tween 20 (Fisher Scientific) (0.01M PBS - Tween 20) and $5 \%$ skim milk (Carnation; Nestle, Don Mills, ON, Canada). They were incubated for $3 \mathrm{~h}$ with either anti-rat ODAM (1:8000) (Moffatt et al., 2008), anti-rat AMTN (1:2000) (Moffatt et al., 2006b), anti-rat SCPPPQ1 (1:2000) (Moffatt et al., 2014), anti-human Cytokeratin 14 (CK14, 1:500, R\&D Systems, Minneapolis, MN) primary antibodies, washed with $0.01 \mathrm{M}$ PBS - Tween 20 for $30 \mathrm{~min}$ followed by treatment with the Dako EnVision ${ }^{\mathrm{TM}}+$ System, peroxidase kit (Dako Corporation, Carpinteria, CA) as recommended by the manufacturer. Visualisation was performed with 3,3'-diaminobenzidine and sections were counterstained with methyl green (Dako Corporation). Negative controls included omission of primary antibody and incubation with pre-immune serum. Sections were examined under an AxioImager M2 microscope (Carl Zeiss, Oberkochen, Germany).

\section{Statistical Analyses}

Means and standard deviations were calculated in Excel and GraphPad InStat (GraphPad, La Jolla, CA). Unpaired $t$ test were used to compare mRNA levels in real-time qPCR and micro-CT VOI. $* p<0.05$.

\section{Results}

\section{General characteristics of Odam KO mice}

Litters generated from HET $\times$ HET crosses had a normal Mendelian distribution of genotypes ( $25 \% \mathrm{WT}, 50 \% \mathrm{HET}$, $25 \% \mathrm{KO}$ ). Both Odam HET and KO mice had no obvious aberrant phenotype and their body weight and size matched that of WT animals from the same age group (data not shown). Mice were fertile and exhibited a normal life span.

Quantitative real-time PCR gene expression analysis Quantitative real-time PCR analyses were performed on RNA extracted from Odam WT, HET, KO mice mandibles using gene-specific Taqman probes for Amtn, Ck14, Odam, Scpppq1 and Tnalp (Fig. 2). The complete inactivation of the Odam gene in $\mathrm{KO}$ was confirmed as there was a total absence of signal using two Taqman probes, one within ([exons 6-7]) and one outside ([exons 9-10]) the targeted region. As expected, HET mice had about half of the level of Odam expression as compared to the WT. In KO mice, there was a slight reduction in Amtn expression and increase for $C k 14$ but these changes were not significant. There was however a significant reduction in Scpppq1 level. Expression of Tnalp was similar in the three groups of mice.

\section{Histological and structural changes in teeth}

Histological analysis (Fig. 3) suggested that tooth formation and structure were not significantly affected by inactivation of the Odam gene (Fig. 3b). The 3 stages of amelogenesis, and in particular maturation where ODAM 
Fig. 2: mRNA levels for Amtn, Ck14, Odam, Scpppq1, Tnalp in Odam WT, HET and KO mice as determined by real-time RT-PCR. All reactions were performed in triplicate and normalised to the levels of beta-actin. Results were expressed $2^{\mathrm{e}(-\Delta \mathrm{Ct})}$ and represent the mean \pm range from 2 independent samples for each genotype. The complete inactivation of Odam gene in $\mathrm{KO}$ mice was confirmed with two probes, one in the targeted region (Odam [6-7]) and one outside (Odam [9-10]). The HET mice shows about half of the level of expression of Odam as the WT. In both HET and KO mice, expression of Amtn was reduced and the one for Ck14 was increased but the differences were not significant. Scpppql level was significantly reduced in KO. No change in Thalp was noted. ${ }^{*} p<0.05$.
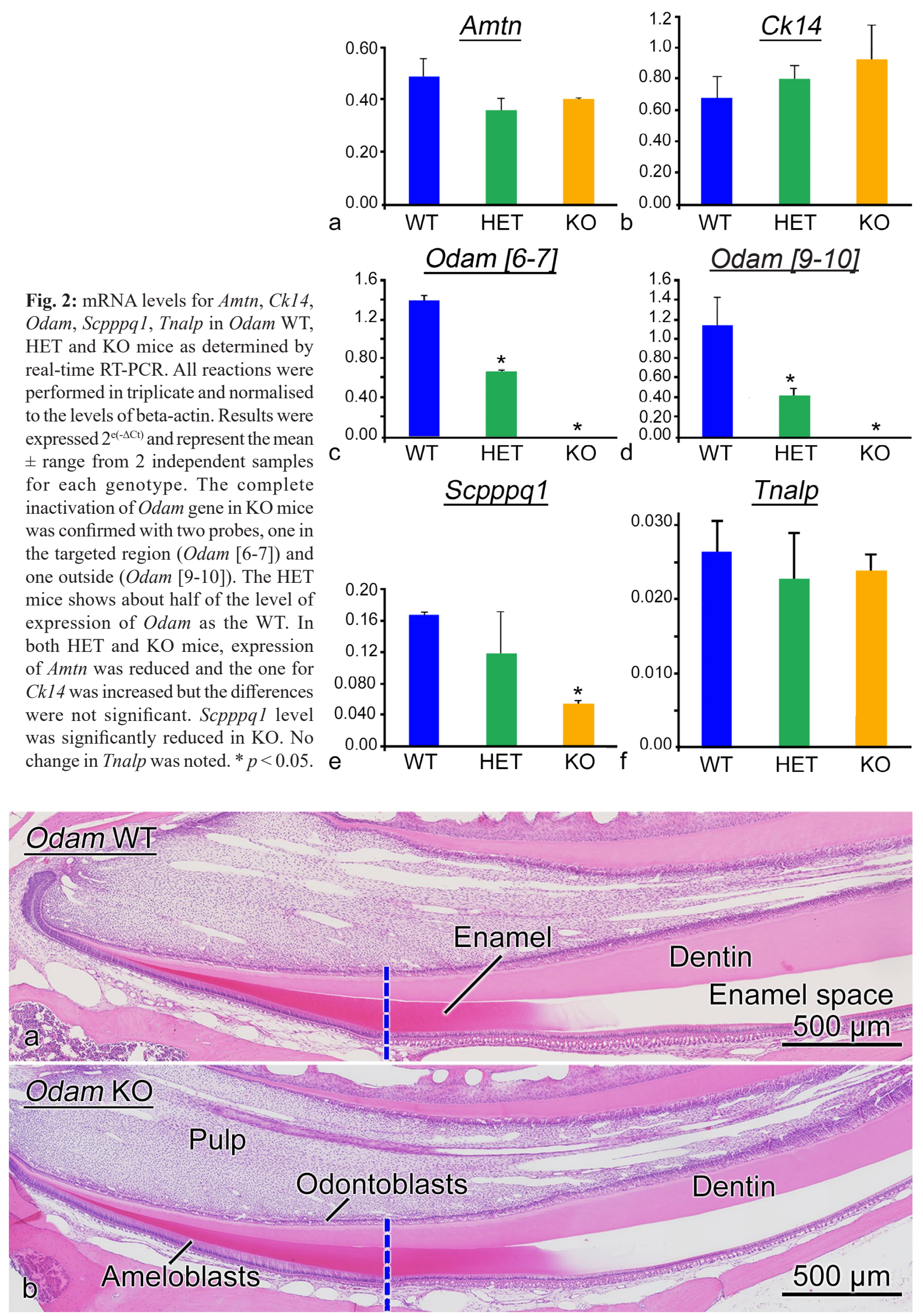

Fig. 3: Haematoxylin-eosin stained sections of 6-months old WT (a) and Odam KO (b) mice incisors. The histology of amelogenesis was comparable between groups. The blue dotted line indicates the start of post-secretory transition stage of amelogenesis. 

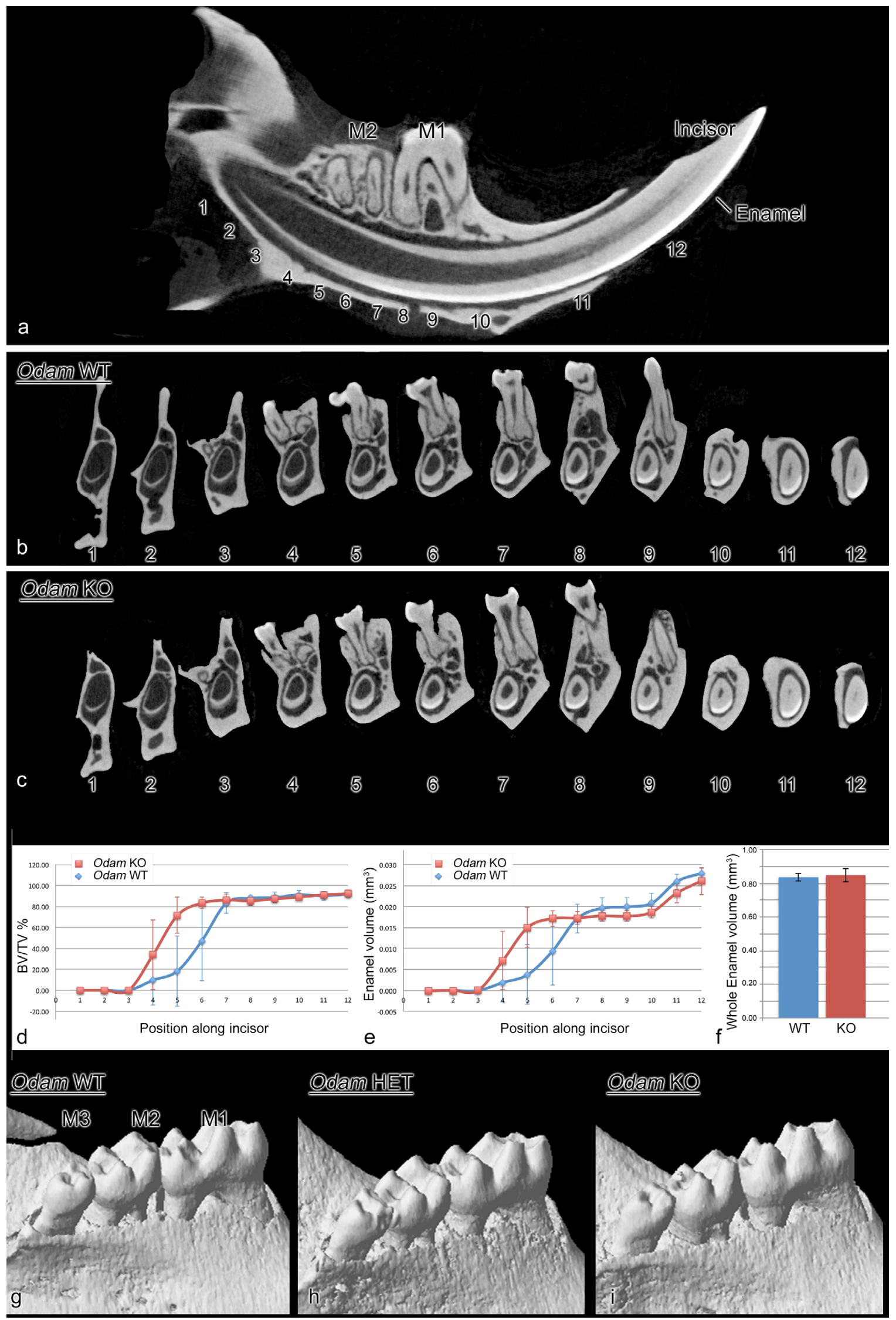

Fig. 4: Microtomographic view of a mandibular incisor for a 6-months old mouse (a). Series of microtomographic reconstructed trans-axial images were taken along the incisor of WT (b) and Odam KO (c) mice. The numbers 1 to 12 indicate the position of the transverse micro-CT X-ray sections were used to measure the volume of interest (VOI) for enamel and determine its mineral density. Quantitative analysis did not reveal any significant difference in enamel density (percentage BV/TV) (d) and volume (e) and whole enamel volume (f). High-resolution 3D renderings of micro-CT of WT (g), HET (h) and Odam KO (i) mice did not show significant difference in abrasion on molar (M1, M2, M3) cusps. 

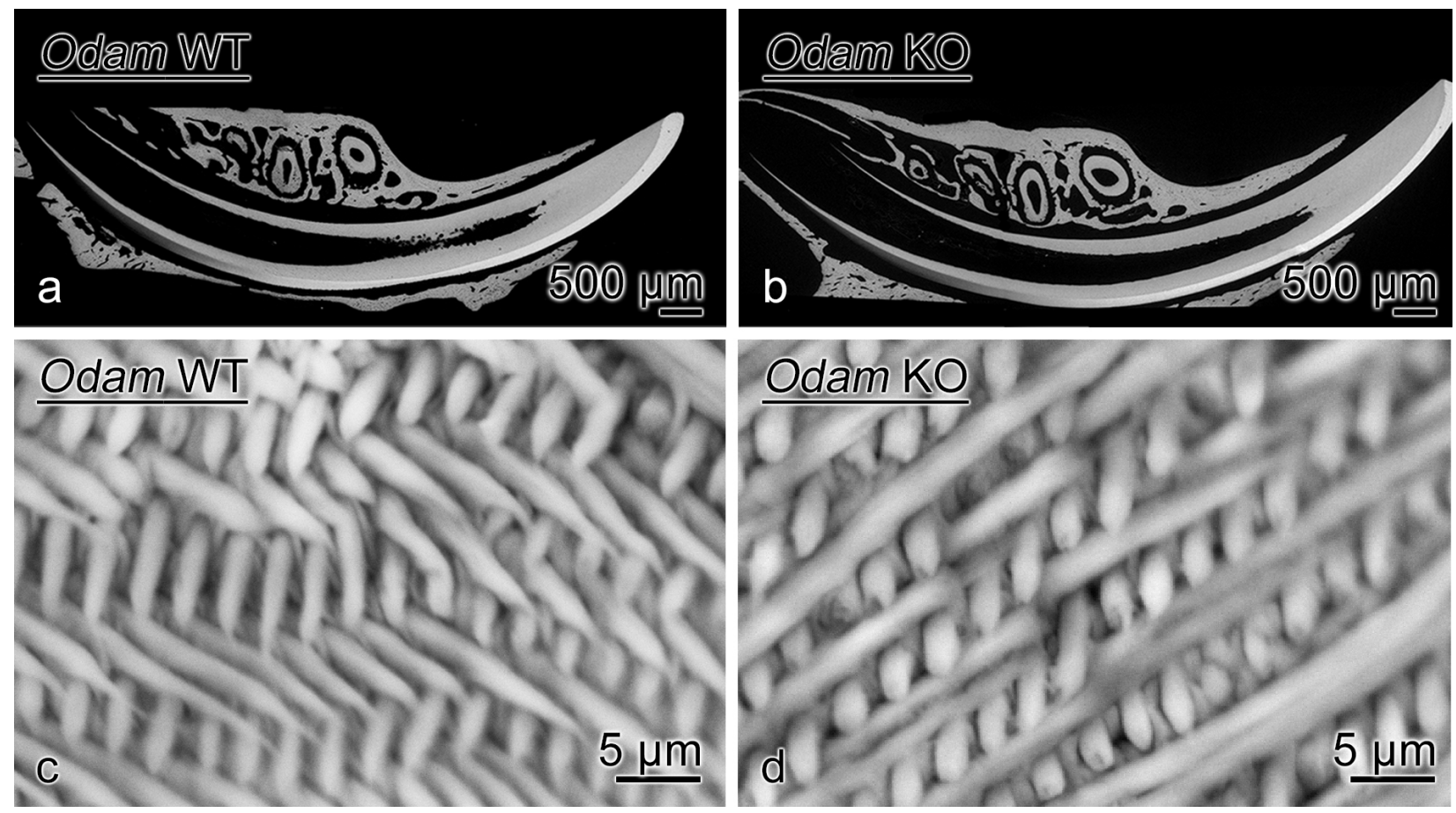

Fig. 5: Backscatter scanning electron microscopy (BEI) of 6-months old WT (a, c) and Odam KO (b, d) mice of sagittally cut incisors $(\mathbf{a}, \mathbf{b})$ and etched fractured incisal tip $(\mathbf{c}, \mathbf{d})$ reveals no obvious delay in enamel mineralisation (compare $\mathbf{a}$ and $\mathbf{b}$ ) and difference in the rod decussating pattern in etched incisor tips, here visualised in slightly different planes of fracture (compare $\mathbf{c}$ and $\mathbf{d}$ ).

is normally expressed, showed similar cellular organisation as in HET (data not shown) and WT (Fig. 3a) mice.

Macroscopic comparison of incisors and molars from Odam KO mice with those from HET and WT mice revealed no obvious difference in structural integrity (size, attrition, chipping) and coloration of enamel (data not shown). No significant difference in overall enamel mineral density (Fig. 4d) and enamel volume (Fig. 4e, f) was found by quantitative CT-Scan analysis and BEI-SEM (Fig. 5a, b) of lower incisors. In addition, no difference was observed in the decussating enamel rod pattern (Fig. 5c, d). Three-dimensional CT-scan renderings (Fig. 4g-i) and SEM (Fig. 6a, b) of molars further confirmed no differences in abrasion among the 3 groups. Survey analyses did not reveal any obvious effect on alveolar bone in $\mathrm{KO}$ mice (data not shown).

\section{LacZ reporter gene expression in Odam KO mice}

The lacZ reporter gene was included in the Odam targeting strategy to further validate its gene expression (Fig. 7). In continuously erupting incisors of Odam KO mice, beta-galactosidase nuclear staining was first detected in late post-secretory transition ameloblasts (Fig. 7i), and its expression became more intense as maturation progressed toward the gingival margin (Fig. 7j, k). JE cells surrounding molars were also stained (Fig. 71). No betagalactosidase activity was found during the presecretory and secretory stages of amelogenesis (Fig. 7g, h), and in other tooth-associated cells such as odontoblasts, pulp cells, cementoblasts, periodontal ligament fibroblasts, and bone cells. A similar staining pattern was obtained with HET mice (data not shown), and no staining was observed in sections from WT animals (Fig. 7a-f).
Histological changes in the $\mathrm{JE}$

The newly formed JE in young Odam KO mice housed in the transgenic facility appeared normal (data not shown). However, as animals became older or were kept in the non-sterile animal facility, some histological alterations to JE became evident (Fig. 8). The dentogingival junction appeared to flake-off and detached from the tooth surface (Fig. 6b, d). There was accumulation of inflammatory cells in the JE (Fig. 8f), the presence of local parakeratinisation (Fig. 8b), and the JE frequently extended along the root (Fig. 8d). While these changes were also present in some WT (Fig. 8a, c) and HET (data not shown) mice, they were less pronounced histologically.

\section{Immunohistochemistry for AMTN, ODAM, SCPPPQ1 and, CK14 in the JE}

As previously reported in WT animals (Dos Santos Neves et al., 2012; Moffatt et al., 2008; Nishio et al., 2010), ODAM localised at the JE-tooth interface and among cells of the JE (Fig. 9c) while AMTN (Fig. 9a) and SCPPPQ1 (Fig. 9d) localised to the cell-tooth interface only. Immunolabelling for CK14 (Fig. 9b) was found throughout the JE. At all ages, ODAM labelling was completely abolished in $\mathrm{KO}$ mice (Fig. 9g), confirming the real-time qPCR results (Fig. 2) and inactivation of the gene. While there was no difference in distribution of AMTN (Fig. 9e) and SCPPPQ1 (Fig. 9h), there was a tendency for the staining to be slightly weaker in the Odam KO mice, an observation consistent with the real-time qPCR results above. In some, but not all, KO mice examined, the labelling intensity of CK14 appeared slightly higher (Fig. 9f) which may explain the non-statistical difference observed by real-time qPCR (Fig. 2b). 

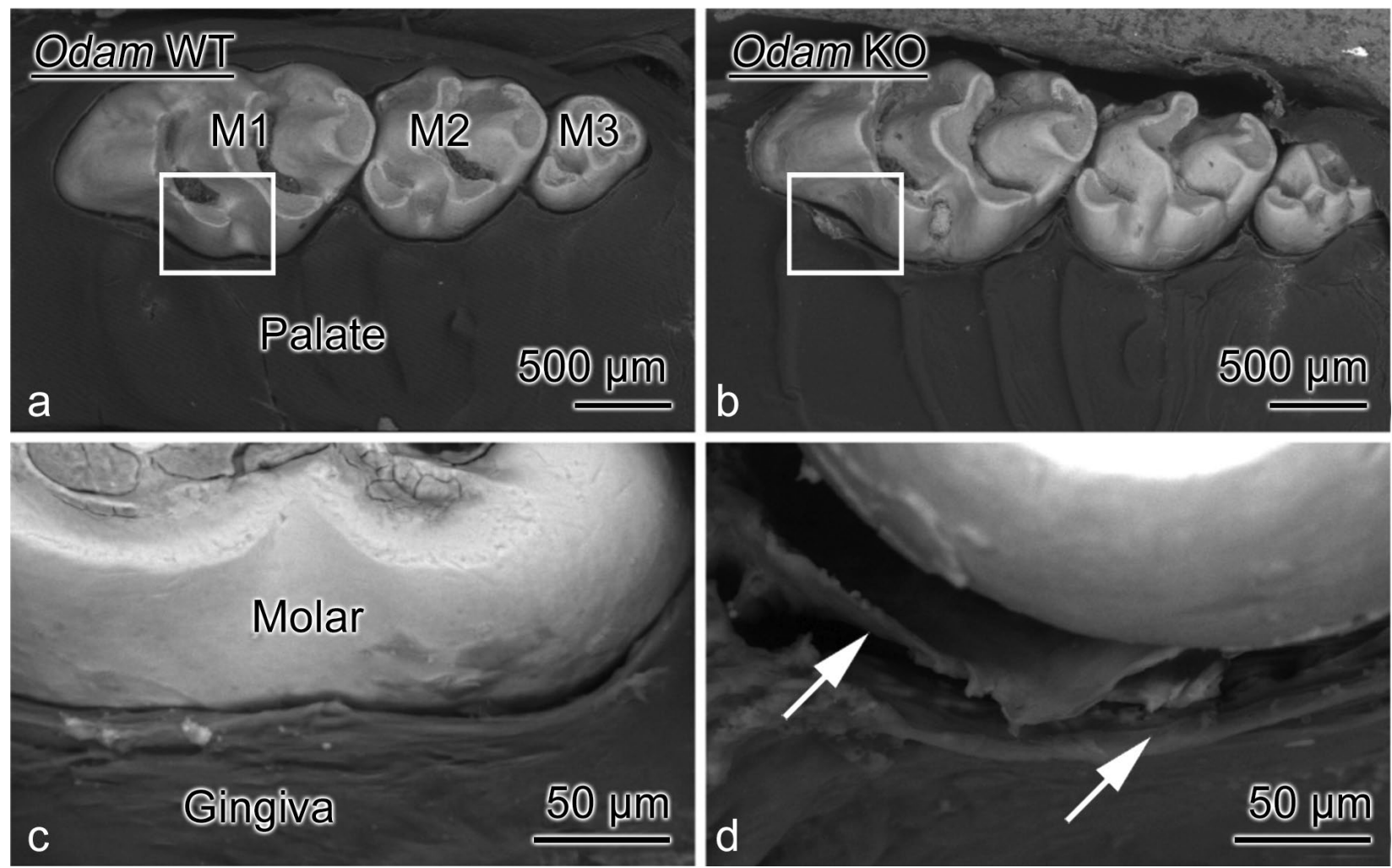

C
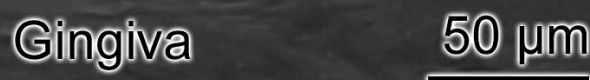

Fig. 6: Scanning electron microscopy of WT (a, c) and Odam KO (b, d) mice dentogingival junction. In absence of $\operatorname{ODAM}(\mathbf{b}, \mathbf{d})$, the dentogingival junction appears to 'flake off' from the tooth surface (arrows). High magnification (c, d) of the boxed areas in $(\mathbf{a}, \mathbf{b})$, respectively.

\section{Regeneration of the JE after gingivectomy}

Gingivectomy was used to test whether the JE phenotype of the Odam KO mice could be exacerbated and if the capacity to form a secondary JE was affected by inactivation of the Odam gene. During the surgical procedure, it was noted that the removal of epithelial tissue surrounding the tooth was easier in Odam KO mice, suggesting a weakness in the structural integrity of the JE. Despite this, regeneration of the JE occurred in WT and KO (Fig. 10) but histological analysis indicated that healing lagged behind with Odam KO mice (Fig. 10d-f). At 7 days post-surgery, the regenerating JE in WT mice was already discernible and was in contact with the tooth surface (Fig. 10b). This was not the case for Odam KO (Fig. 10) mice. At day 14, the JE in WT mice was fully reformed (Fig. 10c). On the other hand, the histology of the regenerating JE in Odam KO mice (Fig. 10f) resembled that of WT mice on day 7.

\section{Occurrence of tumors in Odam KO mice}

Since ODAM has been associated with a number of epithelial tumours, we have paid particular attention to the visual presence of any abdominal, neck and skin masses in sacrificed animals. No masses were observed in all WT $(n=26)$, HET $(n=43)$ and Odam KO $(n=88)$ mice, including one year-old ones housed in the transgenic or non-sterile animal facility. This suggested that the incidence of spontaneous epithelial tumorigenesis at these sites was not affected by inactivation of the Odam gene.

\section{Discussion}

ODAM is a protein with no known homologues and without readily recognisable motifs that would provide insights into its function or activity (Moffatt et al., 2008). Its discrete localisation in the atypical BL attaching epithelial cells to tooth surfaces suggests that ODAM may be implicated in this 'adhesive relationship' (Dos Santos et al., 2012; Moffatt et al., 2008; Nishio et al., 2010). In addition, distinctively from AMTN and SCPPPQ1, two sister proteins that are also present in the $\mathrm{BL}$, it is continuously expressed throughout the JE and appears early during JE regeneration further suggesting that ODAM plays a role in forming the JE and maintaining periodontal integrity (Nishio et al., 2010). In order to determine the function of ODAM in the context of the whole-animal biology, we have created an Odam KO mouse model. Complete inactivation of Odam expression was attested by real-time qPCR with probes within and outside the target region, and by the total absence of immunohistochemical reactivity. $\mathrm{KO}$ mice did not exhibit a tooth phenotype. However, aging animals, as well as those challenged by housing them in a non-sterile facility and by carrying out gingivectomies, showed alterations that replicated some aspects of periodontal disease.

As a possible matricellular protein, ODAM would be expected to have both cellular and matrix implications. Indeed, we see changes that reflect both these functions. At the matrix level, the JE in the $\mathrm{KO}$ was more easily removed during gingivectomy and 'flaking off' of the JE was observed in older animals and not in any consistent 

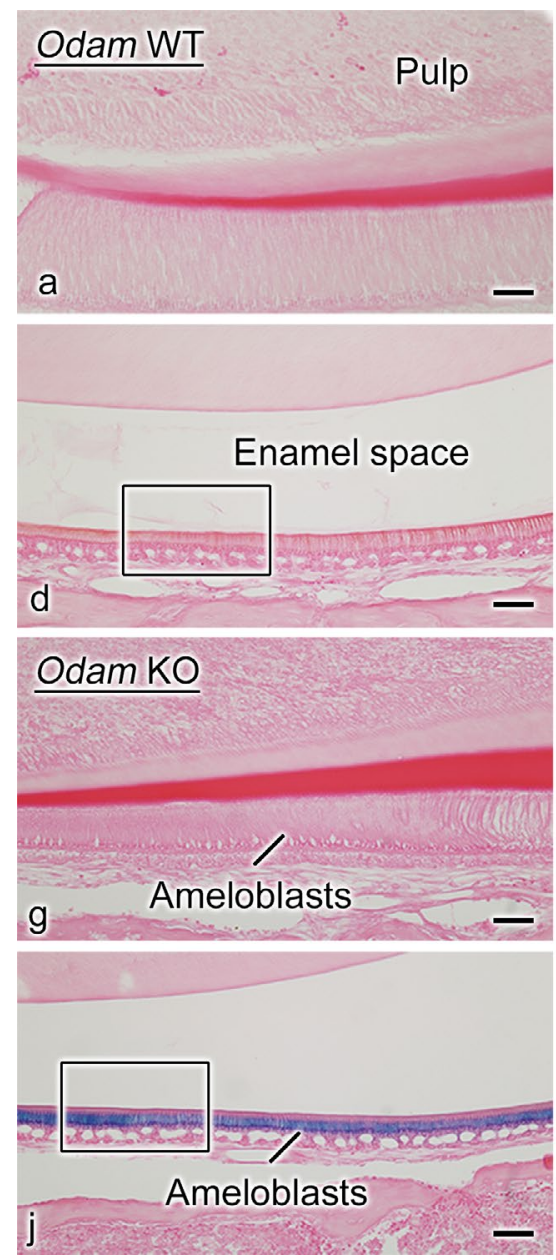
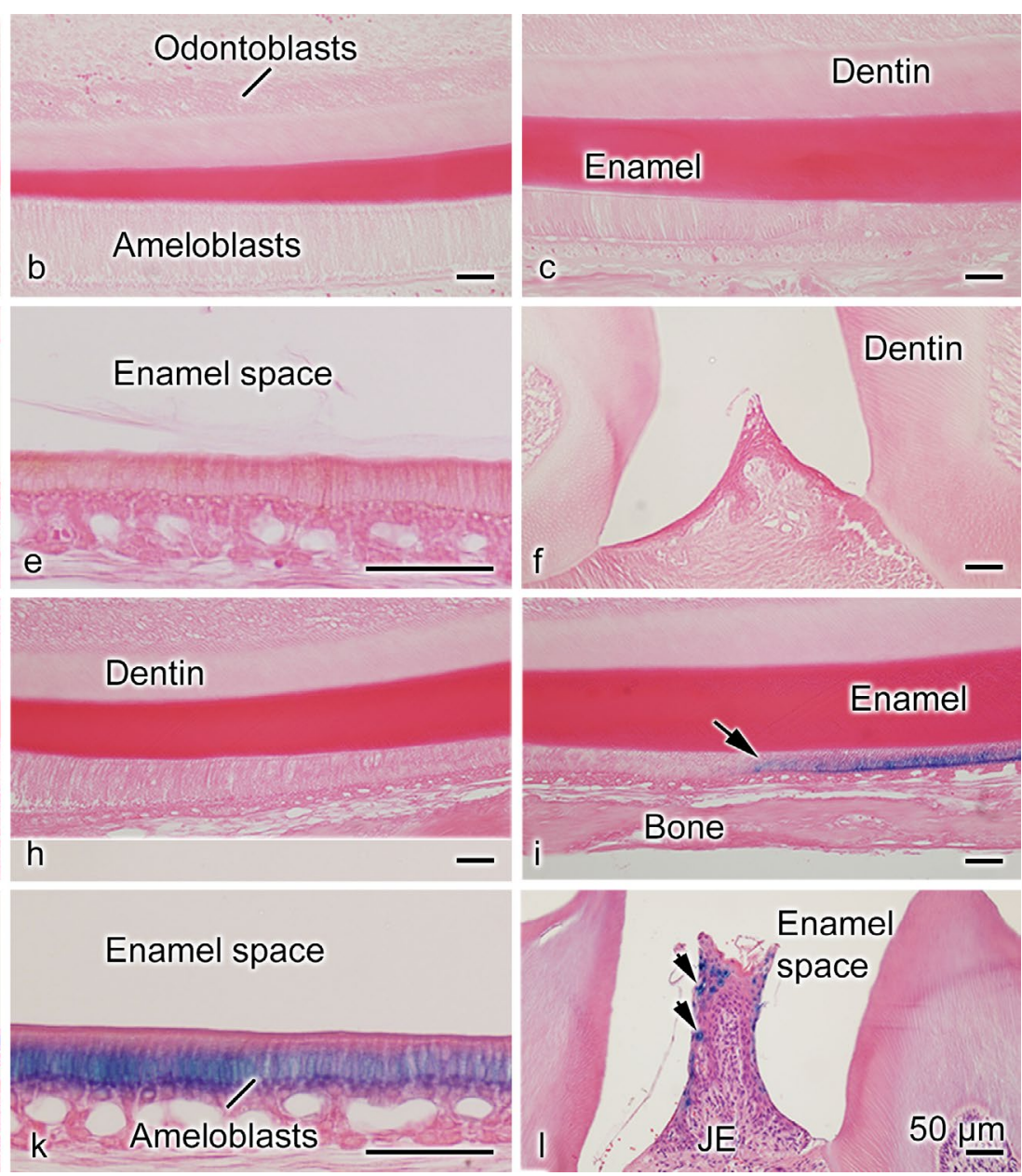

Fig. 7: Histochemical detection of beta-galactosidase activity in WT (a-f) and Odam KO (g-l) mice continuously growing incisors. Nuclear localised beta-galactosidase activity starts in late post-secretory transition where ODAM is normally expressed late post-secretory transition ameloblasts (i, arrow), and its expression became more intense as maturation $(\mathbf{j}, \mathbf{k})$ progressed toward the gingival margin. A positive signal was also observed in cells of the junctional epithelium (l, arrowhead). No expression was observed during secretory stages $(\mathbf{g}, \mathbf{h})$ of amelogenesis and other tooth-associated cells such as odontoblasts, pulp cells and bone cells. No staining was observed in sections from WT animals (a-f). Counterstain is eosin. High magnification $(\mathbf{e}, \mathbf{k})$ of the boxed areas in $(\mathbf{d}, \mathbf{j})$, respectively.

way in younger $\mathrm{KO}$ or older WT mice, suggesting that the absence of ODAM weakens the adhesive relationship between the JE and the tooth surface. This is consistent with the observed trend in reduced expression of Amtn and the significant decrease for that of Scpppq1 in the JE of KO mice. At the cellular level, 6 and 12 month-old mice, in particular when housed in the non-sterile facility, showed more mononuclear cell infiltrate and long JEs, which extended to variable levels along the root. Furthermore, the slower healing of the JE in $\mathrm{KO}$ mice following gingivectomy shows that ODAM contributes to rebuilding the JE.

A recent paper by Lee et al. (2015) raises the exciting possibility that periodontal disease is associated with the loss of detectability of ODAM from the JE and its presence in crevicular fluid. While attractive, this hypothesis does not explain how the level of ODAM in crevicular fluid, which is subject to rapid turnover, would be maintained while it is no longer produced by the JE. The authors also linked $\mathrm{JE}$ adhesion to the tooth surface and periodontal integrity to fibronectin/laminin-integrin-ODAM-ARHGEF5-RhoA signalling, which presupposes that ODAM is a cytoplasmic protein. ODAM has a signal peptide and is a secreted protein that accumulates extracellularly in the atypical BL attaching maturation stage ameloblasts and JE cells to the tooth surface (Dos Santos Neves et al., 2012; Moffatt et al., 2008; Nishio et al., 2013). A cytoplasmic pool of ODAM could arise by internal translation of the normal Odam transcript or by the presence of an alternate transcription site of the gene yielding a transcript lacking a signal peptide but there is no current evidence to this effect. However, the fact that the JE in young $\mathrm{KO}$ mice is not significantly affected (effects only appear with age), that maturation stage ameloblasts at all ages appear structurally normal, and that JE regeneration still occurs in the Odam KO argues against the proposed signalling cascade. Additional studies will be needed to identify signalling pathways implicating ODAM, and perhaps here we can benefit from what happens in tumour cells (see below).

ODAM is also expressed by maturation stage ameloblasts (Dos Santos et al., 2012; Moffatt et al., 2008). However, we have not observed substantial alterations in 


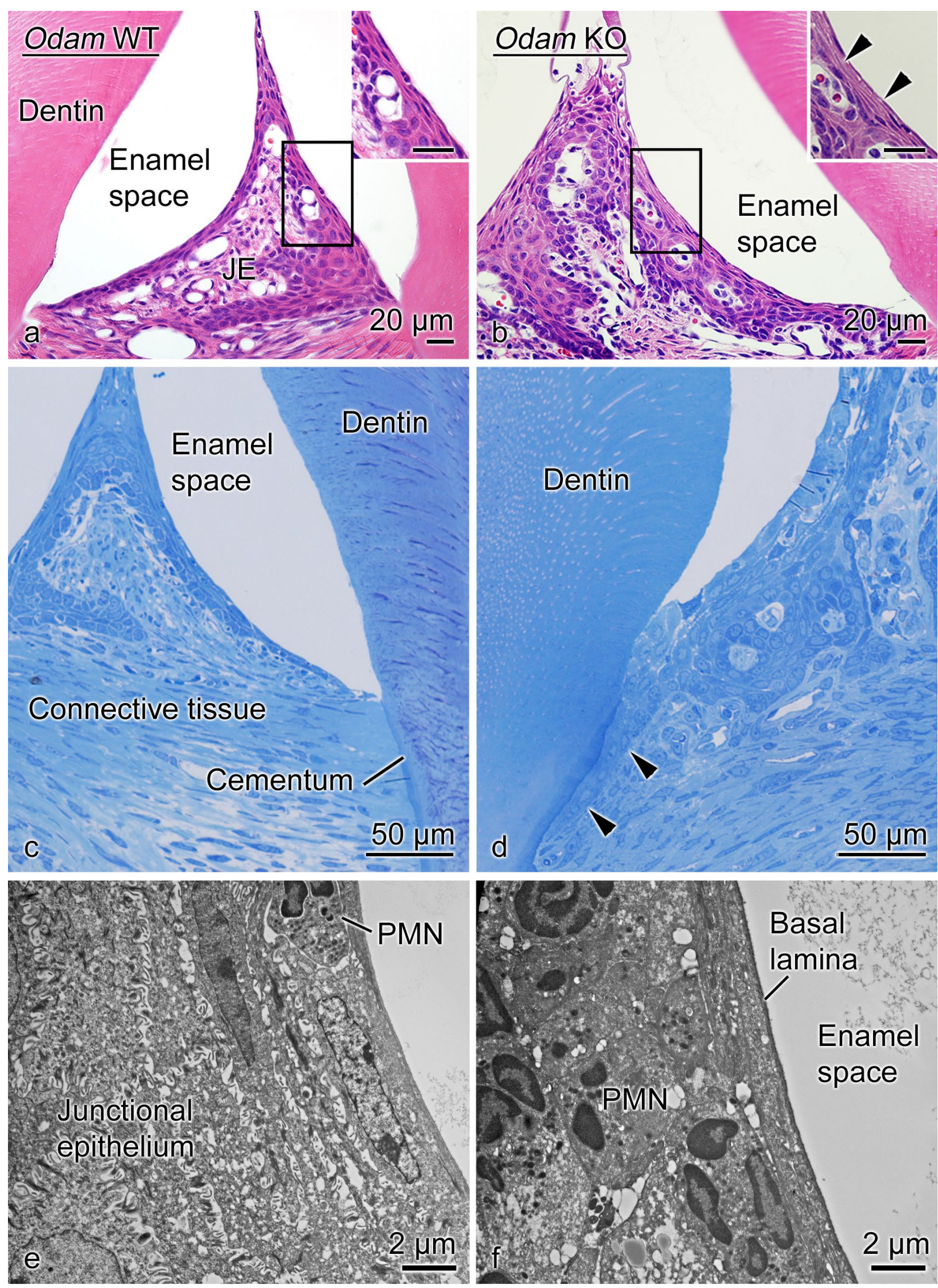

Fig. 8: Histological sections (a-d) and transmission electron micrographs (e-f) of WT (a, c, e) and Odam KO (b, d, f) mice dentogingival junction. Haematoxylin-eosin stained $(\mathbf{a}, \mathbf{b})$ and toluidine blue stained semi-thin $(\mathbf{c}, \mathbf{d})$ sections of the interdental junctional epithelium (JE) from WT (e) and Odam KO mice (f). Inactivation of the Odam gene causes structural changes to the JE including the presence of regions of apparent parakeratinisation (b, inset, arrowhead) and apical extension of the JE along the root (d, arrowhead). (e) Increased infiltration of polymorphonuclear leukocytes (PMN, neutrophil) in the JE in Odam KO mice were noted at the ultrastructural level. 


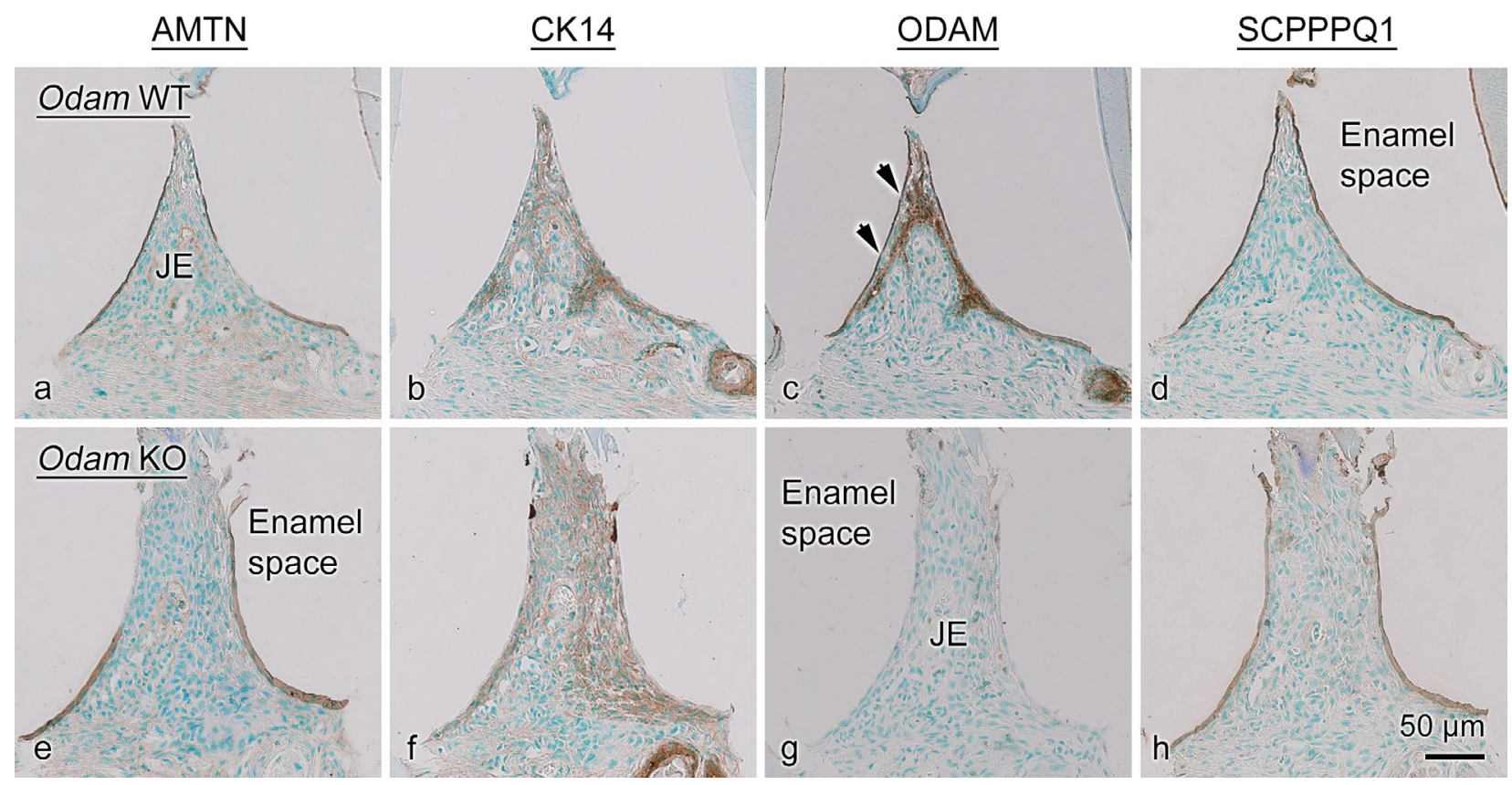

Fig. 9: Immunohistochemical preparations for $\operatorname{AMTN}(\mathbf{a}, \mathbf{e}), \operatorname{CK} 14(\mathbf{b}, \mathbf{f}), \operatorname{ODAM}(\mathbf{c}, \mathbf{g})$ and SCPPPQ1 (d, h) in interdental junctional epithelium (JE) from WT (a-d) and Odam KO mice (e-h). While in WT and KO animals, $\operatorname{AMTN}(\mathbf{a}, \mathbf{e})$ and SCPPPQ1 $(\mathbf{d}, \mathbf{h})$ localised at the JE-tooth interface, the intensity of labelling tended to be slightly weaker in KO mice. (c) The ODAM labelling was present at JE-tooth interface (arrowheads) and among cells of the JE of WT animals (g), however it was completely abolished in KO mice. Expression of CK14 was noted throughout the JE $(\mathbf{b}, \mathbf{f})$ and it was a little more intense in $\mathrm{KO}$ mice $(\mathbf{f})$.

\section{Day 3}
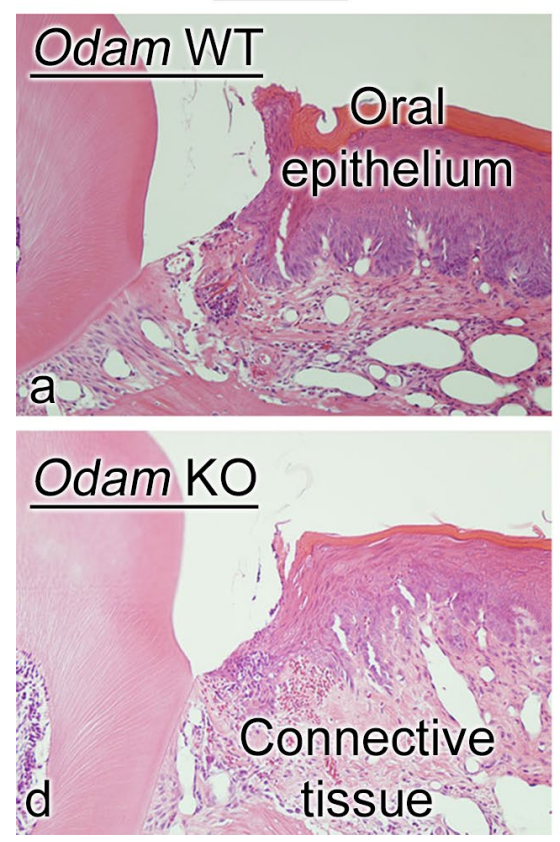

Day 7
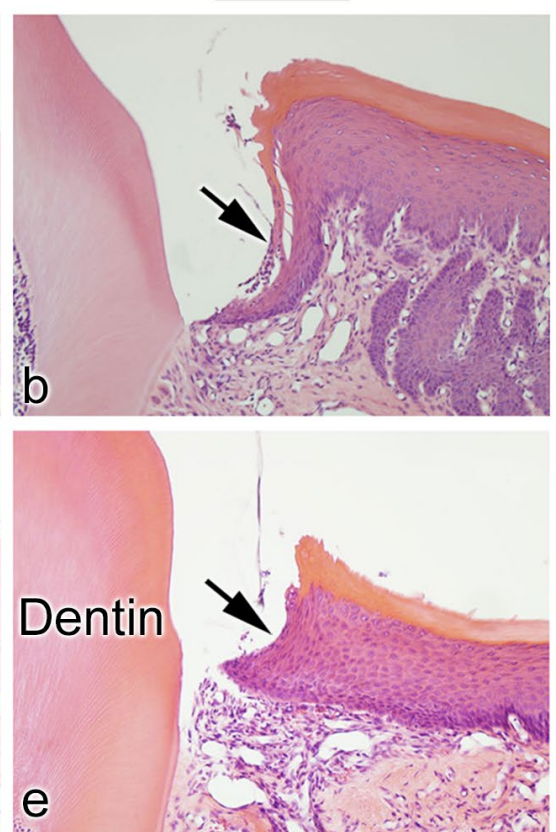

Day 14

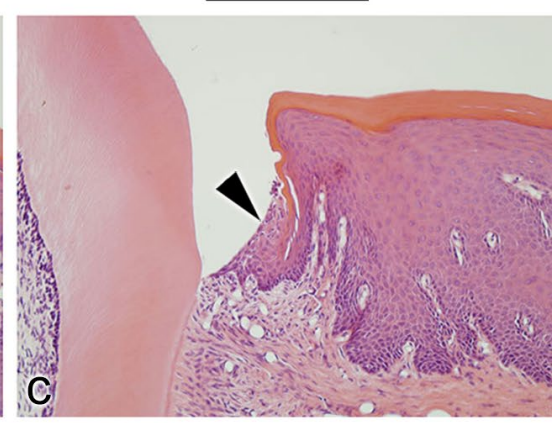

Fig. 10: Light microscopy of gingival wound healing following gingivectomy in Odam WT (a-c) and KO (d-f) mice. In normal animals, at 3 days post-surgery (a), the oral epithelium started to migrate towards the tooth, by 7 days (b) the regenerating JE (arrow) was in contact with the tooth surface and was completely reformed at $14 \mathrm{~d}$ (c), arrowhead). Regeneration of the JE also occurred in $\mathrm{KO}$ (d-f) but histological analyses suggest that it lagged behind. The regenerated JE in KO mice at day 14 (f) resembled that of WT at day 7 (b).

enamel of Odam KO mice. AMTN, a sister SCPP protein that is expressed by maturation stage ameloblasts and also localises to the atypical BL, has been proposed to influence the surface mineralisation of the enamel layer (Lacruz et al., 2012; Nakayama et al., 2015). Nakayama et al. (2015) reported "subtle mineralisation changes" in the lower incisor only of the Amtn KO. Although the authors indicated that "statistical significance was not established" they concluded that "AMTN played a critical role" in enamel formation. The subtleness of Amtn KO phenotype was further emphasised in a perspective by Bartlett and Simmer (2015). It should be pointed out here 
that the surface (final) enamel layer is normally abraded away on occlusal surfaces and any subtle change in its level of mineralisation is therefore not expected to affect the long term functionality of enamel. Indeed, molars in the Amtn KO did not show aberrant abrasion (Nakayama et al., 2015).

Kestler et al. (2011) reported that ODAM limits the growth of breast cancer and human melanoma (Foster et al., 2013) cells and could therefore act as an inhibitor of tumour development. However, they noted that their findings are inconsistent with the apparent high levels of expression in more advanced malignancies (Siddiqui et al., 2009). Their studies have also highlighted the changes in PTEN (phosphatase and tensin homolog on chromosome 10 tumour suppressor gene) expression, a molecule implicated in the phosphoinositide 3-kinase (PI3K)/protein kinase B (AKT) pathway (Foster et al., 2013). The latter is a critical regulator of cellular processes that promote the transformation of a normal to a cancer cell. Clearly, the role of ODAM in epithelial cancers is more complex than suspected, and whether ODAM is an inhibitor or a promoter of tumour growth remains to be resolved. The fact that we did not see an increase in the spontaneous occurrence of tumours in $\mathrm{KO}$ mice lends support to the hypothesis that ODAM would have promoter activity. A possible role of ODAM in neoplasia is further supported by the implication of other SCPP members with matricellular protein activity in tumour progression and metastasis (Wong and Rustgi, 2013).

In conclusion, we demonstrate here that the absence of ODAM has no major effect on enamel, similarly to what has been reported for the Amtn KO. However, unlike the Amtn $\mathrm{KO}$ in which the "integrity of the JE appeared unaffected" (Nakayama et al., 2015), the Odam KO has a pronounced effect at the level of the JE. It maybe that during tooth formation these two sister proteins could compensate for each other. The difference in outcome at the level of the JE between Odam and Amtn KO may reflect the fact that ODAM is not only found at cell-tooth interfaces but is also continuously present among the cells of the JE. Indeed, AMTN may only be transiently expressed in the JE (Sawada et al., 2014) and actually appears late during JE regeneration (Nishio et al., 2010). Like other MPs (Roberts, 2011), it would be expected that the activity of ODAM is contextual, which would explain the increase in severity of the JE phenotype with age in the $\mathrm{KO}$ and delay in regeneration following gingivectomy. While the precise role of ODAM remains to be determined, its expression by the unique incompletely differentiated JE and its association with dedifferentiating epithelial neoplastic cells suggest that ODAM may participate in modulating cell status. The increased severity of JE defects, in particular the increase in inflammatory infiltrate, with age under conventional housing conditions (as opposed to sterile transgenic facilities) further suggest that ODAM may also relate to local inflammatory activity. The JE is a perpetually inflamed structure and the presence of ODAM among cells of the JE may contribute in maintaining a 'proper basal level' of inflammation. This would be consistent with the implication of other SCPP members with matricellular protein activity (e.g. osteopontin and SPARC), in inflammatory conditions, autoimmune diseases, and evasion of the inflammatory response by tumour cells (Piconese et al., 2011; Wai et al., 2006). Altogether, these data position ODAM as a potential target for novel therapeutic interventions aimed at preventing, maintaining, and possibly reverting the ravages of periodontal diseases. Further studies, under conditions leading to more severe periodontal changes, will be needed to fully assess the importance of ODAM in the pathogenesis of this disease.

\section{Acknowledgements}

We extend our thanks to Mrs Cynthia Török for technical assistance. This study was supported in part by the Canadian Institutes of Health Research, the Network for Oral and Bone Health Research and by the Shriners of North America. Dr. Moffatt is supported by the Shriners of North America. Dr. Shingo Kuroda is an Associate Professor in the Department of Orthodontics and Dentofacial Orthopedics at The University of Tokushima Graduate School of Oral Sciences, Japan, and was visiting researcher at the Laboratory for the Study of Calcified Tissues and Biomaterials, Faculty of Dentistry, Université de Montréal, Canada.

\section{References}

Aung PP, Oue N, Mitani Y, Nakayama H, Yoshida K, Noguchi T, Bosserhoff AK, Yasui W (2006) Systematic search for gastric cancer-specific genes based on SAGE data: melanoma inhibitory activity and matrix metalloproteinase-10 are novel prognostic factors in patients with gastric cancer. Oncogene 25: 2546-2557.

Bartlett JD, Simmer JP (2015) New perspectives on Amelotin and amelogenesis. J Dent Res 94: 642-644.

Bonass WA, Kirkham J, Shore RC, Brookes SJ, Godfrey CL, Robinson C (1998) Identification of rat enamel organ RNA transcripts using differential-display. Connect Tissue Res 39: 249-256.

Boskey AL (2006) Assessment of bone mineral and matrix using backscatter electron imaging and FTIR imaging. Curr Osteoporos Rep 4: 71-75.

Bosshardt DD, Lang NP (2005) The junctional epithelium: from health to disease. J Dent Res 84: 9-20.

Dos Santos Neves J, Wazen RM, Kuroda S, Francis Zalzal S, Moffatt P, Nanci A (2012) Odontogenic ameloblast-associated and amelotin are novel basal lamina components. Histochem Cell Biol 137: 329-338.

Foster JS, Fish LM, Phipps JE, Bruker CT, Lewis JM, Bell JL, Solomon A, Kestler DP (2013) Odontogenic ameloblast-associated protein (ODAM) inhibits growth and migration of human melanoma cells and elicits PTEN elevation and inactivation of PI3K/AKT signaling. BMC Cancer 13: 227.

Hogan B, Beddington R, Costantini F, Lacy E (1994) Manipulating the mouse embryo: a laboratory manual, second edition. Cold Spring Harbor Laboratory Press, Cold Spring Harbor, NY, pp 289-307. 
Iwasaki K, Bajenova E, Somogyi-Ganss E, Miller M, Nguyen V, Nourkeyhani H, Gao Y, Wendel M, Ganss B (2005) Amelotin - a Novel Secreted, Ameloblast-specific Protein. J Dent Res 84: 1127-1132.

Kawasaki K (2009) The SCPP gene repertoire in bony vertebrates and graded differences in mineralized tissues. Dev Genes Evol 219: 147-157.

Kawasaki K (2011) The SCPP gene family and the complexity of hard tissues in vertebrates. Cells Tissues Organs 194: 108-112.

Kestler DP, Foster JS, Bruker CT, Prenshaw JW, Kennel SJ, Wall JS, Weiss DT, Solomon A (2011) ODAM expression inhibits human breast cancer tumorigenesis. Breast Cancer (Auckl) 5: 73-85.

Kestler DP, Foster JS, Macy SD, Murphy CL, Weiss DT, Solomon A (2008) Expression of odontogenic ameloblastassociated protein (ODAM) in dental and other epithelial neoplasms. Mol Med 14: 318-326.

Lacruz RS, Nakayama Y, Holcroft J, Nguyen V, Somogyi-Ganss E, Snead ML, White SN, Paine ML, Ganss B (2012) Targeted overexpression of amelotin disrupts the microstructure of dental enamel. PLoS One, 7: e35200.

Lee HK, Ji S, Choung HW, Choi Y, Lee HJ, Park SY, Park JC (2015) Odontogenic Ameloblast-associated Protein (ODAM) Mediates Junctional Epithelium Attachment to Teeth via Integrin-ODAM-Rho Guanine Nucleotide Exchange Factor 5 (ARHGEF5)-RhoA Signaling. J Biol Chem (2015) 290: 14740-14753.

Loughna S, Henderson D (2007) Methodologies for staining and visualisation of beta-galactosidase in mouse embryos and tissues. Methods MolBiol 411: 1-11.

Malaval L, Wade-Gueye NM, Boudiffa M, Fei J, Zirngibl R, Chen F, Laroche N, Roux JP, Burt-Pichat B, Duboeuf F, Boivin G, Jurdic P, Lafage-Proust MH, Amedee J, Vico L, Rossant J, Aubin JE (2008) Bone sialoprotein plays a functional role in bone formation and osteoclastogenesis. J Exp Med 205: 1145-1153.

Moffatt P, Smith CE, Sooknanan R, St-Arnaud R, Nanci $A$ (2006a) Identification of secreted and membrane proteins in the rat incisor enamel organ using a signal-trap screening approach. Eur J Oral Sci 114 Suppl 1: 139-146.

Moffatt P, Smith CE, St Arnaud R, Nanci A (2008) Characterization of Apin, a secreted protein highly expressed in tooth-associated epithelia. J Cell Biochem 103: 941-956.

Moffatt P, Smith CE, St-Arnaud R, Simmons D, Wright JT, Nanci A (2006b) Cloning of rat amelotin and localization of the protein to the basal lamina of maturation stage ameloblasts and junctional epithelium. Biochem J 399: 37-46.

Moffatt P, Wazen RM, Dos Santos Neves J, Nanci A (2014) Characterisation of secretory calcium-binding phosphoprotein-proline-glutamine-rich 1: a novel basal lamina component expressed at cell-tooth interfaces. Cell Tissue Res 358: 843-855.

Murphy CL, Kestler DP, Foster JS, Wang S, Macy SD, Kennel SJ, Carlson ER, Hudson J, Weiss DT, Solomon A (2008) Odontogenic ameloblast-associated protein nature of the amyloid found in calcifying epithelial odontogenic tumors and unerupted tooth follicles. Amyloid 15: 89-95.
Nakayama Y, Holcroft J, Ganss B (2015) Enamel Hypomineralization and Structural Defects in Amelotindeficient Mice. J Dent Res 94: 697-705.

Nanci A, Bosshardt DD (2006) Structure of periodontal tissues in health and disease. Periodontol. 2000 40: 11-28.

Neiss WF (1984) Electron staining of the cell surface coat by osmium-low ferrocyanide. Histochemistry $\mathbf{8 0}$ : 231-242.

Nishio C, Wazen R, Kuroda S, Moffatt P, Nanci A (2010) Expression pattern of odontogenic ameloblastassociated and amelotin during formation and regeneration of the junctional epithelium. Eur Cells Mater 20: 393-402.

Nishio C, Wazen R, Moffatt P, Nanci A (2013) Expression of odontogenic ameloblast-associated and amelotin proteins in the junctional epithelium. Periodontol. 2000, 63: 59-66.

Piconese S, Costanza M, Tripodo C, Sangaletti S, Musio S, Pittoni P, Poliani PL, Burocchi A, Passafaro AL, Gorzanelli A, Vitali C, Chiodoni C, Barnaba V, Pedotti R, Colombo MP (2011) The matricellular protein SPARC supports follicular dendritic cell networking toward Th17 responses. J. Autoimmun 37: 300-310.

Rittling SR, Novick KE (1997) Osteopontin expression in mammary gland development and tumorigenesis. Cell Growth Differ 8: 1061-1069.

Roberts DD (2011) Emerging functions of matricellular proteins. Cell Mol Life Sci 68: 3133-3136.

Sawada T, Yamazaki T, Shibayama K, Kumazawa K, Yamaguchi Y, Ohshima M (2014). Expression and localization of laminin 5, laminin 10, type IV collagen, and amelotin in adult murine gingiva. $\mathrm{J}$ Mol Histol 45: 293-302.

Siddiqui S, Bruker CT, Kestler DP, Foster JS, Gray KD, Solomon A, Bell JL (2009) Odontogenic ameloblast associated protein as a novel biomarker for human breast cancer. Am Surg 75: 769-775.

Wade-Gueye NM, Boudiffa M, Laroche N, VandenBossche A, Fournier C, Aubin JE, Vico L, Lafage-Proust MH, Malaval L (2010) Mice lacking bone sialoprotein (BSP) lose bone after ovariectomy and display skeletal site-specific response to intermittent PTH treatment. Endocrinology 151: 5103-5113.

Wai PY, Guo L, Gao C, Mi Z, Guo H, Kuo PC (2006) Osteopontin inhibits macrophage nitric oxide synthesis to enhance tumor proliferation. Surgery 140: 132-140.

Wong GS, Rustgi AK (2013) Matricellular proteins: priming the tumour microenvironment for cancer development and metastasis. Br J Cancer 108: 755-761.

Yoshitake H, Rittling SR, Denhardt DT, Noda M (1999) Osteopontin-deficient mice are resistant to ovariectomyinduced bone resorption. Proc Natl Acad Sci U S A 96: 8156-8160.

Editor's Note: All questions / comments by the reviewers were answered by text changes. There is hence no Discussion with Reviewers section. Scientific Editor in charge of the paper: Thimios Mitsiadis. 